\title{
Víctor J. Vázquez Alonso, Laicidad y Constitución, Centro de Estudios Políticos y Constitucionales, Madrid 2012 (ISBN: 978-84-259-1542-0, 670 páginas)
}

No hace falta insistir demasiado en la enorme repercusión que la laicidad estatal ha tenido en la conformación del tipo Estado Constitucional. En realidad, Estado Constitucional y Estado laico son conceptos sinónimos, idénticos. La coherencia del Estado Constitucional exige un compromiso con la laicidad. El respeto a los derechos fundamentales demanda un Estado consecuente con la laicidad.

Una obra reciente y muy meritoria profundiza en esta categoría dogmática. Una obra cuyo autor es el profesor Víctor J. Vázquez Alonso y en cuyo origen está el trabajo de investigación que presentó para la colación del grado de doctor en la Universidad de Salamanca. Una obra que prologa Augusto Martín de la Vega, director de la tesis, ofreciendo algunas de las claves de la misma, y en la que, a continuación, a lo largo de tres capítulos dedicados a la laicidad en los EEUU, Francia y España, el doctor Vázquez Alonso reflexiona acerca de temas muy diversos, pero entrelazados por el sentido y alcance de la laicidad o aconfesionalidad estatal. Y, en fin, una obra que acredita de sobra oficio intelectual, solvencia investigadora y originalidad.

Esta recensión no pretende ni resumir la obra ni utilizarla en su totalidad. En lo que sigue, tan sólo trataré de aportar algunas reflexiones nacidas, de un modo inmediato, de su lectura. Las reflexiones del autor, y algunas mías al hilo de las suyas, serán las que quedarán expuestas aquí. Y ello con el único propósito de animar la lectura de un libro que se aproxima con lucidez y claridad expositiva a un tema clave, insisto, desde la perspectiva constitucional.

Laicidad y Constitución acredita, desde luego, un manejo y análisis exhaustivo de bibliografía y fuentes de investigación valiosas, principalmente fuentes documentales y escritas -las llamadas fuentes secundarias-. Evidencia, asimismo, un profundo conocimiento de la jurisprudencia constitucional -no sólo española, también americana y francesa- y del Tribunal Europeo de Derechos Humanos. Es un trabajo predominantemente doctrinal, centrado en la doctrina jurídica, si bien salta a la vista que el autor conoce la jurisprudencia constitucional más relevante sobre el tema. Si bien no comparto algunas de las hipótesis y conclusiones del trabajo, hay que reconocer que todas ellas se defienden razonable y fundadamente. El trabajo es muy honesto.

Si no me equivoco, el propósito principal que anima la obra es definir la singularidad o particularidad de la laicidad en tanto categoría jurídicoconstitucional autónoma (aunque fundada en la libertad religiosa y claramente incidida, en algunos países, por el mandato de cooperación) y, en tal sentido, analiza con solvencia lo que podría considerarse su núcleo esencial: «el carácter esencialmente limitador de la laicidad». Frente al derecho de libertad religiosa (art. 16.1 CE) y al principio de cooperación (art. 16.3 in 
fine), eminentemente positivos, la laicidad es una categoría restrictiva o limitadora de la acción estatal. La laicidad es, en esencia, lo contrario de la confesionalidad. Lo no eclesiástico ni religioso, lo civil.

Comparto, quede dicho desde el comienzo, la idea matriz del trabajo. Tengo la impresión de que el reto de una adecuada protección de la libertad e igualdad religiosa pasa por definir con mayor precisión la dimensión meramente negativa de la aconfesionalidad, la indiferencia o distancia entre lo público y lo religioso, hoy difuminada y justificada, desde posturas doctrinales que no comparto, en base a la denominada laicidad positiva o a puntos de vista si cabe aún más confusos. La laicidad es, ante todo, una situación, con estatus político y jurídico, que garantiza la separación y la neutralidad en materia de conciencia y religión.

El art. 16.3 de nuestra Constitución proclama, en efecto, que «ninguna confesión tendrá carácter estatal» e impide, por ende, que los valores o intereses religiosos se erijan en parámetros para medir la legitimidad o justicia de las normas y actos de los poderes públicos. Al mismo tiempo, el citado precepto constitucional veda cualquier tipo de confusión entre funciones religiosas y funciones estatales. Por otra parte, de una lectura conjunta de los arts. 14 y $16.3 \mathrm{CE}$ se deduce que no es posible establecer ningún tipo de discriminación o de trato jurídico diverso e injustificado de los ciudadanos en función de sus ideologías o sus creencias y que debe existir un igual disfrute de la libertad religiosa por todos los ciudadanos (así, entre otras, SSTC 24/1982, 141/2000 o 101/2004).

Tomando en consideración el carácter esencialmente limitador o negativo de la laicidad, la distinción entre separación y neutralidad en la que se apoya casi toda la reflexión del trabajo es muy adecuada.

En este contexto, el autor opta por un enfoque de Derecho Comparado y analiza conjuntamente las experiencias de laicidad americana, francesa y española, a fin de apreciar sus semejanzas y diferencias, las causas de tales semejanzas y diferencias, pero también, y sobre todo, para confrontar el entendimiento, e incluso la implementación legislativa, que se ha hecho en estos países de la aconfesionalidad a la luz de un debate riquísimo, mucho más maduro en todo caso en los EEUU y Francia que en España.

Sin embargo, entiendo que esa confrontación debiera aprovecharse o explicitarse aún más; podría sacarse más utilidad de la perspectiva comparada, ya sea en el capítulo español, ya sea en el capítulo de conclusiones. Los tres modelos analizados no son compartimentos estancos. El autor es perfectamente consciente de ello, pero se echa de menos una mayor insistencia en la lectura que se podría hacer de la aconfesionalidad española a la luz de la laicité francesa y el wall of separation de los EEUU.

De otra parte, como admite el autor, el trabajo es eminentemente teórico o especulativo. Lo que sucede es el autor no se resiste a comprobar sus hipótesis en la "práctica», significativamente en el capítulo español (financiación y enseñanza), pero también en el capítulo americano (ayuda estatal 
a la religión) y francés (legislación sobre usos de signos religiosos, desde la perspectiva de la jurisprudencia del TEDH). Creo que el trabajo no requería esa comprobación, sin perjuicio de incluir alguna referencia a esas cuestiones al hilo de la reflexión en torno al contenido conceptual de la laicidad. El trabajo, con esa comprobación, pierde algo de altura o profundidad.

El trabajo, como indicaba al inicio, se adentra en un tema constitucional clásico, que esté en el origen mismo del Estado Constitucional, y avanza y profundiza en la línea ya apuntada por otras aportaciones doctrinales. Es fruto, en cualquier caso, de una investigación original realmente valiosa. Su principal mérito es que reflexiona con propiedad en torno a una categoría dogmática, la laicidad estatal, necesitada de clarificación (la referencia de la Gran Sala del TEDH, en su reciente sentencia del caso Lautsi, al margen de apreciación nacional y la ausencia de un consenso europeo en la materia es bien demostrativa), valiéndose, además, de la mejor experiencia habida en el Derecho comparado.

Por lo que concierne más directamente a la doctrina científica española, sorprende la escasa atención prestada a la laicidad o aconfesionalidad, a lo que el Tribunal Constitucional ha denominado la dimensión objetiva de la libertad religiosa (SSTC 46/2001 o 101/2004). Hay estudios, bien conocidos, que se centran en la dimensión subjetiva del derecho (arts. 16.1 y $2 \mathrm{CE}$ ) o en su dimensión prestacional (la cooperación ex art. 16.3) -así, entre otros constitucionalistas, Barrero Ortega: 2006; López Castillo: 2002; Porras Ramírez: 2006-, pero no existen prácticamente monografías específicas sobre la laicidad. La obra del profesor Vázquez Alonso viene, en tal sentido, a llenar un hueco, desde luego en la doctrina constitucionalista.

Para concluir, quisiera tan sólo apuntar una reflexión personal sobre las relaciones Estado-Iglesias en general y el entendimiento que en Europa se ha hecho del binomio libertad religiosa-laicidad en particular. Una reflexión animada por la lectura de Laicidad y Constitución y que pone de manifiesto la necesidad de seguir profundizando en la laicidad como categoría constitucional, más allá de que, en este tema, como en otros muchos, pueda constatarse que Constitución racional-normativa e histórica suelen ir de la mano.

En el espacio europeo hay que comenzar constatando, ante todo, la existencia de una variedad de modelos de relación entre el Estado y las confesiones religiosas, fundados todos ellos en la libertad e igualdad religiosas $\mathrm{y}$, con frecuencia pero no siempre, en la laicidad. Se puede constatar, por otro lado, una tendencia clara hacia la llamada laicidad cooperativa, que hace conciliable la aconfesionalidad con las relaciones de cooperación entre los poderes públicos y las confesiones religiosas. Cabría, más exactamente, diferenciar tres modelos o paradigmas, a falta de un consenso europeo en la materia (STEDH, caso Lautsi).

El primer modelo sería el de las Iglesias de Estado. Las Constituciones de aquellos países que apuestan por este modelo consagran expresamente la libertad religiosa, pero intentan armonizar dicho principio con la 
existencia de una Iglesia oficial o nacional. Algunos modelos clásicos de iglesia de Estado, como Suecia, Finlandia y Noruega, están inmersos en un proceso constitucional que está provocando el desestablecimiento de sus respectivas iglesias oficiales. La sumisión de la Iglesia al Estado aparece recogida expresamente en la Constitución de Dinamarca, mientras que en el caso de Finlandia y Suecia se realiza una remisión al Derecho del Estado en lo referente a la regulación de sus Iglesias nacionales, aunque la tendencia es que la Iglesia oficial disfrute de una gran independencia del Estado. La Constitución griega establece que la Iglesia ortodoxa griega es la oficial y la somete al ordenamiento del Estado, e incluso le concede el estatus jurídico de corporación de Derecho público, pero paralelamente garantiza el derecho de gobierno interno de la confesión religiosa. El supuesto inglés puede calificarse como el de una iglesia de Estado de carácter teórico, pero de separación fáctica. La jurisprudencia constitucional nacional y la jurisprudencia del Tribunal Europeo (STEDH, caso Folguero) certifica, por lo demás, las dificultades de conciliar, en estos países, el reconocimiento de la libertad e igualdad religiosas con el status oficial o cuasi oficial, sea como sea privilegiado, de una concreta confesión religiosa. ¿Libertad religiosa auténtica o más bien tolerancia de cultos?

El segundo modelo sería el modelo laico, que incluye la neutralidad y la separación (Francia, aun con matices como apunta Vázquez Alonso, sigue siendo la referencia). La neutralidad implica no sólo la igualdad de trato entre las confesiones, sino también entre lo religioso y lo no religioso. La separación entre el Estado y las confesiones religiosas implica la independencia de ambos, que los criterios religiosos no se erijan en parámetros para medir la legitimidad o justicia de las normas y actos de los poderes públicos, eludiendo cualquier tipo de confusión entre funciones públicas y religiosas. La laicidad tiene un sentido esencialmente limitador. Al Estado le está prohibido convertirse en protector de los dogmas, poner la vida pública bajo el signo de una o varias confesiones o asumir la fe de la mayoría sociológica del pueblo. Cualquiera de estas actuaciones supondría una violación de la libertad e igualdad religiosas. La aconfesionalidad comporta, ante todo, la desobligación, por parte del Estado, de atenerse en su legislación a una doctrina religiosa particular referente a la conformación de la sociedad civil. Y por lo que concierne al tratamiento jurídico de las convicciones, la laicidad exige que el Estado ofrezca a los grupos ideológicos y religiosos una misma estructura jurídica a la que hacer centro de imputación de derechos y obligaciones. La atribución de esta estructura común para todos supone el reconocimiento constitucional de la igualdad de las mismas ante la ley. La igualdad no excluye dispensar un trato desigual a supuestos de hecho que en sí mismos son desiguales para contribuir precisamente a la promoción de la igualdad real. Por tanto, el reconocimiento por parte del Estado de las peculiaridades de los sujetos colectivos de la libertad religiosa no quebraría la igualdad. Sin embargo, este reconocimiento tendrá siempre como límite 
la no discriminación, esto es, que no se menoscabe la igual condición de sujetos de derechos y libertades de todas las convicciones, ideológicas y religiosas, sin una causa objetiva y razonable.

El tercer modelo es el de aquellos países en teoría aconfesionales pero en los que se dan reminiscencias confesionales, más o menos acusadas (así, España, Italia o Alemania). El intento de ampliar el contenido de la libertad religiosa desde su origen liberal hasta la acción positiva de los poderes públicos ha acabado propiciando unos resultados distintos de los pretendidos con el fomento de los derechos en el Estado social. Se ahondan las diferencias a favor de los grupos religiosos más poderosos o, directamente, a favor de la confesión mayoritaria. La valoración positiva del fenómeno religioso no es uniforme. En estos países, junto a la posible discriminación entre libertad religiosa e ideológica se puede producir una discriminación interna entre las confesiones. Las relaciones de cooperación podrían contemplarse, desde este enfoque, como un residuo de confesionalidad al que se quiere revestir de una forma moderna y que, en todo caso, no se adapta al sentido profundo del Estado social, sino que más bien lo desvirtúa a través de la potenciación de diferencias y privilegios. Las Constituciones o la legislación de desarrollo de los textos constitucionales privilegian a una confesión religiosa (neoconfesionalidad estricta) o a varias (pluriconfesionalidad) sobre las demás confesiones o ideologías. La dimensión social de la libertad religiosa o, si prefiere, la apertura de la libertad religiosa a la función promocional del Estado social no es, en estos países, una cuestión pacífica. Las relaciones de cooperación, en el marco de llamada laicidad cooperativa, se ha acabado utilizando no tanto para remover obstáculos que impedían el ejercicio de la libertad religiosa sino más bien para legitimar un marco de desigualdad y privilegios incompatible con la auténtica neutralidad.

Queden aquí estas breves consideraciones a modo de simple guión de las principales aportaciones de Laicidad y Constitución. Un libro en el que el profesor Vázquez Alonso acierta a reflexionar en torno a las implicaciones de la laicidad a la luz de la experiencia americana, francesa y española. De su contenido, esta recensión tan sólo ha dado alguna noticia. Que el lector profundice y la disfrute como bien merecen el valioso proyecto editorial del Centro de Estudios Políticos y Constitucionales y el esfuerzo intelectual que hay detrás.

Abraham Barrero Ortega

Universidad de Sevilla 